\title{
UN CÁLIZ DE JUAN DE ASTORGA EN BOLIVIA
}

El trasiego de artistas y obras entre España y América, en uno y otro sentido, fue muy intenso y aun falta bastante para tener un panorama suficientemente completo y sacar consecuencias. Al margen de la identificación concreta de cada uno de ellos, el fenómeno se inscribe en un amplio marco de trasvase cultural donde los aspectos artísticos alumbran los fundamentos sobre los que descansa este proceso de colonización, de tanto alcance en la edad moderna.

Estas líneas dan a conocer un cáliz de plata sobredorada en propiedad privada de La Paz'. Se trata de una obra de platería renacentista que presenta buen estado de conservación, aunque bastante alterado su aspecto por la aplicación posterior de numerosas piezas de esmalte con el fin de enriquecerlo, desfigurando el diseño lineal y sobrio así como su ornamentación plateresca, en pro de una imagen más colorista, propia de un concepto popular del ornamento, con sentido acumulativo.

Las medidas de esta pieza son: $24 \mathrm{~cm}$. de alto, $14^{\prime} 5 \mathrm{~cm}$. de diámetro en la base y $9^{\prime} 7 \mathrm{~cm}$. en el de la copa. En el revés del pie aparecen claramente dos marcas: la localidad y el platero. La impronta del centro artístico corresponde a la ciudad de Cuenca: el cáliz con una estrella de seis puntas sobre la copa, y debajo el anagrama del nombre. El punzón del artífice: «ESTOR/ GA», Juan de Astorga. Por último hay que anotar que la plata ha sido contrastada como puede verse por una burilada, a modo de gusanillo, para comprobar la calidad del metal. Tras las investigaciones de Amelia López-Yarto a las que me remito, podemos conocer la evolución y esplendor de la orfebrería conquense de esta época ${ }^{2}$.

El cáliz muestra una peana circular de tres fajas concéntricas; en la primera y más ancha lucen motivos decorativos de grutescos, máscaras con vegetación alternando con cuatro medallones; tres cabezas de perfil: San Pedro, San Pablo, San Andrés, y la Cruz entre rocas y arboleda. La técnica del cincelado en esta faja va combinada con la del grabado de flores y hojas en la siguiente. La tercera moldura parece lisa dando paso al vástago, con un gollete cilíndrico y arandela de la que nace el nudo en forma de jarrón con costillas muy cortas. Le cubre una arandela plana y de perfil circular que sobresale tras la que continúa el astil con otra pieza cilíndrica, y dos arandelas agallonadas de silueta ondulante recibiendo un capitel. La copa acampanada va ceñida por una rosa o subcopa bulbosa decorada por cabezas de angelotes con los extremos de sus alas anudados unos a otros. Contornea la rosca de la rosa una crestería muy típica en los modelos de la ciudad, visible en los cálices de Albendea y Castejón.

Las numerosas piezas sobrepuestas de esmaltes azules, verdes y amarillos, parecen de técnica champlevé, y van desde sencillas cuadrifolias, otras dobles con hojas en amarillo, pequeños rombos, trapecios, pirámides y ovoides. Más elaboradas son unas cartelas de raigambre manierista en el pie.

Juan de Astorga debió de nacer alrededor de 1555, hijo de Martín de Astorga y Quiteria Román. Entroncó con el mejor orfebre de la ciudad, Francisco Becerril, al casar con Isabel Bautista Becerril, hija de Cristóbal, a su vez hijo de Francisco; todos ellos plateros. Astorga fue nombrado «oficial platero» de la catedral de Cuenca el catorce de abril de 1587, falleciendo seguramente en 1633. Sólo conocemos una obra suya con marca: el copón del Museo Dio-

\footnotetext{
' Sobre la platería en Bolivia puede consultarse el catálogo de la exposición, Cristina Esteras Martín, Platería del Perú Virreinal, 1535-1825, Madrid, 1997.

2 Amelia López-Yarto Elizalde, Francisco Becerril, Madrid, 1991; La Orfebrería del siglo xvı en la provincia de Cuenca, Cuenca, 1998, pp. 350-354.
}

$A E A$, LXXV, 2002, 297, pp. 51 a 88 

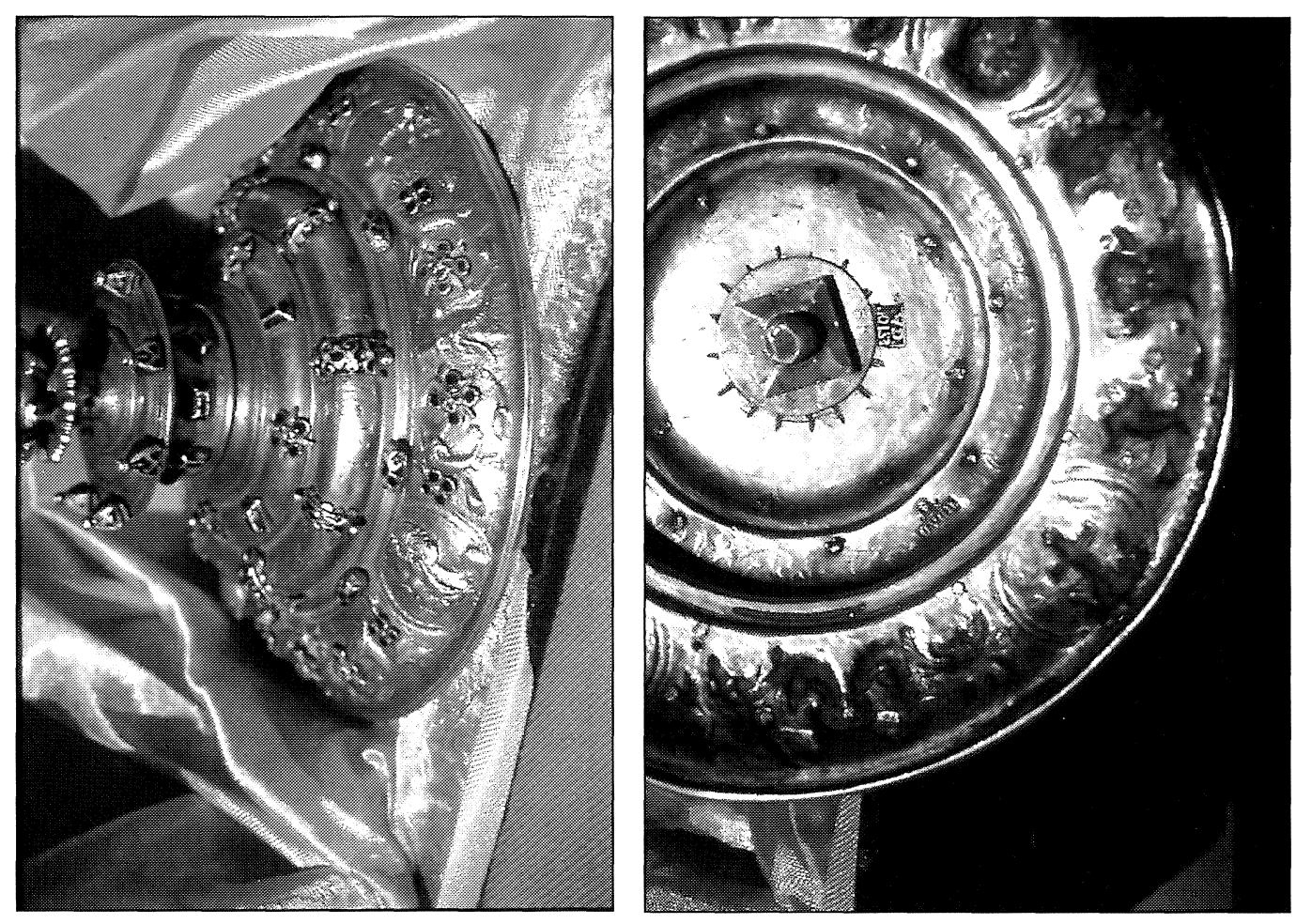

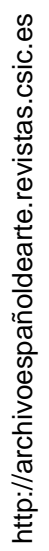

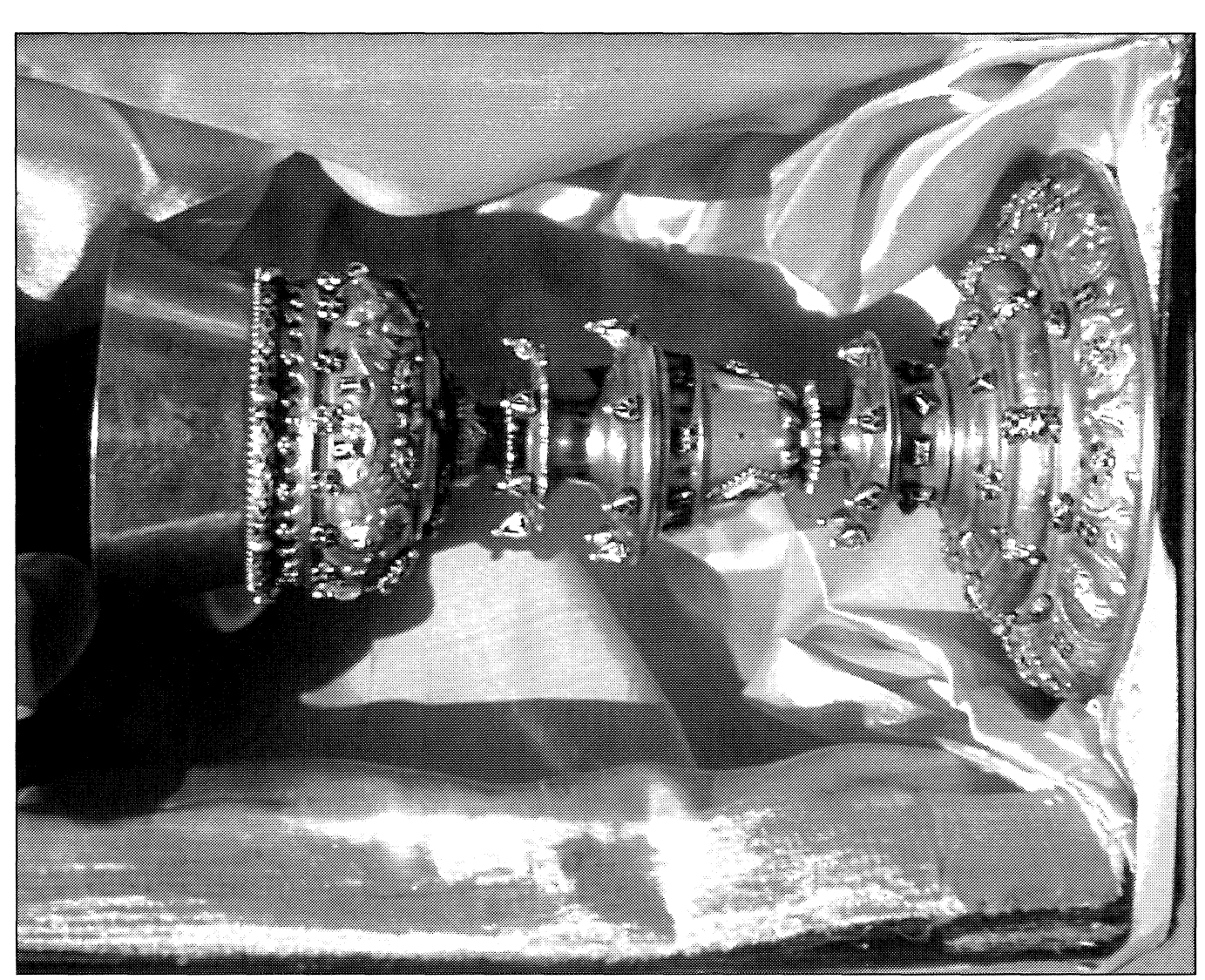

AEA, LXXV, 2002, 297, pp. 51 a 88

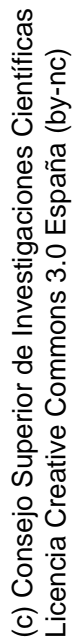


cesano de Cuenca; ahora hay que añadirle este cáliz boliviano. Por su fidelidad a los modelos anteriores de Becerril (especialmente por su nudo en jarrón), podemos asignarle de momento una cronología temprana, en las dos últimas décadas del siglo xvI.

RAFAEL RAMOS SOSA

Universidad de Sevilla

\section{DE NUEVO SOBRE LA COMPASSIO MARIAE: A PROPÓSITO DE LAS PINTURAS MURALES DE SEPULCRO DE DON ALFONSO VIDAL EN LA CATEDRAL VIEJA DE SALAMANCA}

En el verano de 1999 quedaron al descubierto tras su restauración las pinturas murales de estilo gótico lineal de los siglos XIII y XIV que se encontraron en noviembre de 1997 en el brazo meridional del crucero de la catedral vieja de Salamanca ${ }^{1}$. Por su cantidad, por su calidad y por la riqueza de su iconografía estos descubrimientos consolidan la importancia de Salamanca en el panorama de la pintura de estilo gótico lineal. No pretendo abordar en este momento un estudio de conjunto acerca de estas pinturas, que reservo para otra ocasión, sino estudiar un aspecto iconográfico relevante de estos descubrimientos que entronca con el objeto de interés de la profesora Domínguez Rodríguez en un artículo publicado no hace mucho tiempo en las páginas de esta revista ${ }^{2}$.

En el brazo meridional del crucero de la catedral vieja de Salamanca existen cuatro sepulcros monumentales con decoración escultórica y pictórica, dos en el muro oriental y dos en el muro meridional (fig. 1). El objeto de mi interés se encuentra en el sepulcro del muro meridional más próximo a la puerta de Acre (la puerta que, abierta en el muro oriental, comunica con el Patio Chico). De este sepulcro eran ya bien conocidas las pinturas del fondo y del intradós de su arcosolio, con representaciones de la Coronación de la Virgen y de diversos santos (fig. 2). En la reciente restauración se ha descubierto la decoración que completaba el conjunto por encima del arcosolio hasta la línea de imposta. El estilo de estas pinturas murales es muy próximo al del Mateos que firma la espléndida Virgen de Misericordia de la parte alta del muro ${ }^{3}$.

La identificación del personaje a quien corresponde este sepulcro y, con ello, de su cronología ha suscitado algunos problemas puestos de nuevo de actualidad con la aparición en la reciente restauración de inscripciones que han aportado nuevas referencias a esta problemática. Los sepulcros de la catedral vieja de Salamanca apenas merecieron una escueta mención de Ponz. Fue en el siglo xix, más sensible a las realizaciones de la Edad Media, cuando se inició su estudio. La primera obra en la que se ofrece una identificación de estos sepulcros es la

\footnotetext{
${ }^{1}$ La noticia de su descubrimiento se difundió en la prensa local a partir del 13 de noviembre de 1997. Algunos días más tarde el canónigo don Daniel Sánchez recordaba que ya en octubre de 1990 había llamado la atención sobre la existencia de pinturas murales que permanecían ocultas. La existencia de pinturas murales en este emplazamiento había sido advertida ya por Gómez-Moreno, que en el catálogo monumental de Salamanca que redactó entre 1901 y 1903 escribió: «hay señal de haberlas tenido el arquito que encabeza la puerta del Acre, otro arco sepulcral del crucero y asimismo...» (GómezMoreno Martínez, Manuel: Catálogo monumental de España. Provincia de Salamanca, Dirección General de Bellas Artes, Valencia, 1967, p. 133). La obra de Gómez-Moreno permaneció inédita hasta 1967, pero Tormo se sirvió de ella en un estudio publicado ca. 1930 en el que escribió: «Por encima del portón a la calle que se llamó «Puerta de Acre»: se ven restos de pinturas murales» (Tormo y Monzó, Elías: Salamanca: las catedrales (sobre estudios inéditos de don Manuel Gómez-Moreno), Patronato Nacional del Turismo, Madrid, s. a., p. 54).

${ }^{2}$ Domínguez Rodríguez, Ana: «"Compassio" y "Co-redemptio" en las cantigas de Santa María. Crucifixión y Juicio Final», Archivo Español de Arte, tomo LXXI, Madrid, 1998, pp. 17-35.

${ }^{3}$ Gutiérrez Baños, Fernando: «Pintura de estilo gótico lineal en Castilla y León», en XIII Congreso Nacional de Historia del Arte: Ante el nuevo milenio: raíces culturales, proyección y actualidad del arte español (Granada, 2000), Universidad de Granada, Granada, 2000, volumen II, p. 1106, foto 6.
}

AEA, LXXV, 2002, 297, pp. 51 a 88 